\title{
Teens' Perception about Social Networking Sites: Does Facebook Influence Teens' Self-Esteem?
}

\author{
Anastasia Botou, Petros-Stylianos Marsellos \\ Greek Ministry of Education, Athens, Greece \\ Email: botouanastasia@gmail.com, petros.marsellos@gmail.com
}

How to cite this paper: Botou, A., \& Marsellos, P.-S. (2018). Teens' Perception about Social Networking Sites: Does Facebook Influence Teens' Self-Esteem? Psychology, 9, 1453-1474.

https://doi.org/10.4236/psych.2018.96089

Received: May 31, 2018

Accepted: June 26, 2018

Published: June 29, 2018

Copyright ( 2018 by authors and Scientific Research Publishing Inc. This work is licensed under the Creative Commons Attribution International License (CC BY 4.0).

http://creativecommons.org/licenses/by/4.0/

Open Access

\begin{abstract}
Teenagers use social networks on a daily basis; they provide communication and information services and offer the chance to establish new relationships or maintain existing ones. Self-esteem, the esteem we have for our abilities and for what we can achieve, is affected by the comparison with others and by whether we are accepted by them or not. Since social networks enable their users to accept people or not, and they are also spaces highlighting social comparisons, it is important to investigate whether they have impact on teenagers' self-esteem. This paper examines the perceptions of teenagers about social networks and investigates whether Facebook, as a representative of social networks, has impact on teenagers' self-esteem. The survey was conducted among students in Athens, aged $16(\mathrm{~N}=71)$ and the Self Perception Profile for Adolescents (Harter, 1988) questionnaire was used, in its Greek version PATEM IV, adding questions regarding the opinions of teenagers for the use of social networks and their acceptance and popularity, which were correlated with the PATEM IV sub-scales. The study showed that self-esteem is not connected with the frequency with which students use Facebook or the level of acceptance or popularity of the users. It appears that teenagers primarily seek recognition and establishing relationships with their peers through social networks. The closer the relationships, the more they use social networks to communicate and less for self-promotion. The number of "likes" is positively correlated with relationships with the opposite sex. Teenagers with more "likes" on their profile pictures have developed better relationships with the opposite sex. Percentage of $51.6 \%$ expresses the need of higher acceptance and social recognition by others and uses "tags" in order to increase the "likes" received. $87.1 \%$ uses social networks on a daily basis and $57.1 \%$ two hours and more daily, but the majority finds enough time to go out. It is alarming that $53 \%$ of the teenagers sacrifice their sleeping and studying time to find time to
\end{abstract}


use social networks. In general, our research reaffirms the need of teenagers to belong to a group, and also the importance of relationships among peers during adolescence. The vast majority belongs to communities with known persons, using social networks safely, and they believe that they are beneficial. Finally, it appears that Facebook contributes to the establishment of relationships, particularly with the opposite sex.

\section{Keywords}

Social Networks, Facebook Likes, Time Spent on Facebook, Students' Self-Esteem, Teenage Relations

\section{Introduction}

Self-esteem is a multidimensional, dynamic concept related to individual and environmental factors. Therefore, when studying self-esteem, the scientific research focuses on investigating the individual or environmental factors affecting it. Even though there are indications that self-esteem is important as an attitude towards life, the fact that it is not characterized by stability, i.e. it may change depending on age, developments and a person's living conditions (Emler, 2001), makes it hard to determine the factors affecting it. An important factor that is positively connected with self-esteem is the level of acceptance by others. Consequently, the acceptance of teenagers by others and thus by their peers boosts their self-esteem, whereas, on the contrary, rejection leads to low self-esteem. Studies have shown that low self-esteem is a cause creating individual or social problems, like depression, substance abuse, school dropout, risky sexual behaviour and teenage pregnancy, lower relationship satisfaction and criminal behaviour (Huang, 2010; Barry, Grafeman, Adler, \& Pickard, 2007; Caplan, 2003; Kraut, 1998; Steinfield et al., 2008; Harter, 1999, Lan \& Lanthier, 2003; Reinherz et al., 1993; Roberts Gotlib \& Kassel, 1996; Shapira et al. 2007; Rumberger, 1995).

Researchers indicate that the majority of teenagers spend at least 30 minutes daily on social media (Rideout et al., 2010, Al-Jubayer, 2013, Labrague 2014), so a significant part of their communication is performed through a social network and also new relationships are created. The use of social networks has changed the form of relationships and ways of communication. Social networking sites offer services to their users, such as the creation of personal pages, where they can share personal information and experience, upload photos, make new relationships, organize social events, learn about other people's lives as well as express their own ideas and emotions and feel that they are part of a group (Ivcevic \& Ambady, 2012). Haferkamp \& Kramer (2011) suggest that social networks lead to social comparisons, self-evaluation or self-enhancement, which may affect people either positively or negatively. For example, social comparisons affect people positively in cases that inspire them to be like other people they look up to (Lockwood \& Kunda, 1997; Wills, 1981) and in other cases they make them 
feel at a disadvantage and affect them negatively (Marsh \& Parker, 1984; Aspinwall, 1997). Therefore, it is important to investigate the perceptions of teenagers about social networks and to what extent their self-esteem may be related with Facebook, which is one of the most famous. Until today, there are not enough surveys to show us the extent that Facebook impacts the personality or abilities of teenagers. Within this framework, knowing the challenges teenagers are facing, we considered it crucial to investigate whether their self-esteem, which is vital for their development, is affected by Facebook.

Pounders, Kowalczyk, Stowers (2016) claim that people post selfies to gain social acceptance and boost their self-esteem, through the number of likes they receive. The present paper tries to examine the perception of teenagers on the use of social networks and whether Facebook affects teenagers' self-esteem. To this end, a correlation between the degree of acceptance or rejection that teenagers experience by joining Facebook and their level of self-esteem is made. In particular, we measured teenagers' self-esteem and afterwards we investigated the correlation of the self-esteem with the way teenagers make use of Facebook's tools related to acceptance, rejection or popularity, such as the number of friends or "likes" they have on their recent profile pictures or whether they "tag" in order to increase their popularity. What is more, we tried to examine whether teenagers share their personal information, without critical thinking, in order to become popular and whether this is linked with their self-esteem. Finally, we studied the quality of teenager's social life, examining the time spent on Facebook in relation to their interpersonal relationships and everyday occupations, and whether this time is linked with their self-esteem.

\section{Theoretical Framework/Literature Overview}

William James (1890) defined self-esteem as the quotient of successes in relation to our goals: Self-esteem = successes/goals. Rogers (1959) correlates self-esteem with the concept of the ideal self. He focuses on the battle given by humans for their self-actualization. According to Rogers, self-esteem is boosted according to how close we are to what we consider as "ideal self", in other words as we reach our self-actualization. Coopersmith (1967) defined self-esteem as the self-value a person attributes to themselves and is defined through its attitude towards life. Attitudes and behaviours suggest whether a person has low or high self-esteem. Rosenberg (1965) determined a variety of attitudes and, by evaluating people's behaviours and reactions to them, he assessed their self-esteem. He regarded self-esteem as a value judgement towards the self (Emler, 2001).

Henri Tajfel (1978) suggested that people are members of social groups and perceive a part of the feeling of who they are, i.e. their identity, from the members of said groups. The value or the level of the group they belong to affects their perception on their individual value. In other words, social identities are potential sources of self-esteem. On the contrary, other researchers tried to define self-esteem in relation to our relationship with others. When the relation- 
ships are good and someone is accepted, self-esteem is high. When the relationships are bad and someone must be rejected, then self-esteem is low. Therefore, self-esteem is characterized as a state, but also as an element of the personality (Hetherton \& Polivy, 1991).

A definition provided by Scott et al. (1996) for self-esteem is the esteem one has for their value and significance, as well as the responsible behaviour towards others. Emler (2001) on the other hand, claims that the common sense for self-esteem is the positive view one has for himself. Very often, the concept of self-esteem identifies with the concept of self-perception, given that it is structured on it and its basic aspects arise there from (Scott et al., 1996).

According to Scott et al. (1996), self-esteem is an important element for the development of youngsters' responsible behaviour. Their research found out that the development of self-esteem results from various environmental factors, among which lies the school environment. They suggest that self-esteem is identified with responsibility, and the first one is considered as an important catalyst and source of the second one.

Young people in general, regardless of the circumstances, wish for or are inspired almost by the same things, at least at a material level. So, for example, young people coming from underprivileged areas have common conventional ambitions for their adult life, such as a nice home, a good job, a nice car etc. In contrast with this tendency of young people, self-esteem is closer related to the ambitions for personal qualities, which create ambitions that are more variable and lead to different desires and behaviours in some aspects. For example, good looks are something craved by all youngsters, but being likeable is not the case for all (Emler, 2001).

Social self-esteem is a term usually adopted by teenagers and is defined as the evaluation of themselves from the satisfaction they gain from three aspects of their selves: the physical appearance, the romantic attraction and the ability to create and preserve close friendships. It is underlined that the concept of well-being could be also defined as satisfaction which also regards the person's estimation about the satisfaction of their life as a whole (Valkenburg et al., 2006).

There is no other period during which evaluations about one'sself are highly likely to affect a person's self-esteem and well-being such during adolescence. Early and middle adolescence are especially characterised by increased focusing on one's self. Teenagers are often involved in what has been reported as imaginative behaviour. Teenagers tend to overestimate the extent that others observe and evaluate and, therefore, they may be intensely interested in how they look in the eyes of others. Consequently, a significant danger arises from the fact that, in social media, interpersonal comments are often available to all other members of the website. These public evaluations are highly possible to affect the development of social self-respect of teenagers and make them very interested in negative comments for them (Valkenburg et al., 2006).

Social networks are an important research domain for researchers who are interested in new technologies and their social impact. Social networks are web- 
sites allowing people to create a public or semi-public profile within a delimited system, to create a list with other users with whom they share a connection and to watch and go through the list of their connections and the persons connected with it. The first social network appeared in 1997 and nowadays there are hundreds all over the world, supporting a variety of practices and services (Steinfield et al., 2008).

One of the most popular social networks amongst young people is Facebook. Its creation was motivated by the social need of Harvard students to communicate with other persons who were staying at their homes (Steinfield et al., 2008). Facebook and other social networks have replaced the traditional means of communication, and especially among young people. They form an important part of their everyday lives. Through social networks, young people communicate, are informed and create relationships. Facebook offers its users identity and a sense of freedom It also helps shy and introvert people who struggle to take part into conversations, to build a social capital, because it lowers inhibitions, offering the chance to build healthy links and relationships (Ellison, Steinfield, \& Lampe, 2007; Amichai-Hamburger, \& Vinitzky, 2010).

Even though social media are useful, a significant disadvantage arises from their frequent use; people who use them daily are at risk of sharing information that may harm their well-being. Also, people with low self-esteem use social networks to express themselves, considering that they are inside a safe environment (Forest \& Wood, 2012). So in some cases they face understanding and support, whilst in other cases they may face social criticism and social comparisons that could lower their self-esteem. Social networks are correlated with communication and relationships and offer acceptance or rejections through "comments", "likes" and "friend requests". As a result anyone can receive positive or negative feedback or be affected by social comparisons or even face cyber bullying, therefore it is important to investigate how adolescents perceive its use or to what extent it affects their self-esteem.

The research about how social media influence teenagers has been focused on their effects on psychological and emotional state. It has found significant risk factors and their consequences which block teenagers' development. The relationship among self-esteem and social media has so far been examined in a relatively small number of researches. Self-esteem is important for human evolution and is related with psychological or emotional problems. Our research examines in a new way whether Facebook interaction through "likes", "tags" and the number of "friends" influences the teenager's self-esteem. Hence it opens horizons in this scientific field. In addition, it provides an insight of how teenagers perceive their use of social media, how they share information and how it affects their social life.

\section{Research Background}

It is remarkable that a number of surveys have found out that the continuous use of the Internet is connected to several dimensions of loneliness, depression and 
stress. It is believed that this is due to the fact that the weaker relationships created online have replaced stronger relationships that used to exist, such as those with family and friends (Steinfield et al., 2008).

Shaw \& Gant (2002) claimed that, as the number of people using the Internet increases, so will the number of studies examining the effects of its use in their psychological health. The study of Kraut and his partners (1998) concluded that the use of the Internet is positively connected with depression, loneliness and stress, leading to the negative view of the public concerning the Internet. In their study, Shaw \& Gant (2002) made the proposition that the use of the Internet may affect the users beneficially. The participants took part in five conversations with an anonymous partner. At three different time points, measuring scales of depression, loneliness, self-esteem and social support were offered. The changes in their scores were observed along the years. The use of the Internet was found to decrease significantly loneliness and depression, while their social support and self-esteem increased remarkably (Shaw \& Gant, 2002).

Steinfield et al., (2008) reviewed the studies regarding the implications of the Internet and social networks on people's mental health. They found out that there are studies showing that their use is neither connected with factors such as reduced communication or neglect of the family, nor with the extent of loneliness and depression. In fact, their finding that the implications of the Internet on a person's mental health differentiate according to the degree of the user's introversion or extroversion is particularly interesting. Extroverts are more likely to gain positive benefits from the use of the Internet and social networks than introverts. Generally, they verify that most researchers claim that the use of the Internet and social networks has positive effects on the users' mental well-being (Steinfield et al., 2008).

Valkenburg et al. (2006) wanted to investigate the impacts of social networks (e.g. Friendster, My Space) on teenagers' self-esteem and well-being. The study was carried among 881 teenagers (10 - 19 years old) who had an online profile on a social network in the Netherlands. According to the findings of the study, the frequency of the use of the social network had an indirect impact on their social self-esteem and well-being. The use of the social network boosted the number of relationships created, the frequency of the feedback received by teenagers about their profiles and the quality of comments they were receiving, i.e. positive VS negative comments. It is pointed out that the positive feedback on the users' profiles improved teenagers' social self-esteem and well-being, while negative feedback reduced their self-esteem and well-being (Valkenburg et al., 2006).

Barker's study (2009) is particularly interesting, as it assessed the motives for the use of social networks. The motives examined where those of group anonymity, collective self-esteem and impacts of gender on teenagers. Communication with members of the peer group was the most important motive for the use of social media. The participants with high self-esteem had strong incentives to communicate with their peers through social networks. It is worth mentioning 
that teenage girls were more likely to report higher positive self-esteem and broader use of social media in total, in order to communicate with their peers. Negative self-esteem was correlated with social compensation, which implies that those who had negative feelings for their social group used social media as an alternative to communicate with other group members. Boys were more likely than girls to report negative self-esteem and use of the social media as a social compensation and social satisfaction of their identity (Barker, 2009).

The study of Kramer \& Winter (2008) states that social media are popular means to communicate one's personality. It focuses on the factors that define this particular form of self-presentation and the extent of self-revelation in those media. A survey among 58 users of a German social network and a content analysis of the participants' profiles showed that self-efficiency as for the management of appearances is closely connected with the number of virtual friends, the degree of the profile's details, and the style of the personal picture. The results show also a small impact of extroversion, whereas there was no significant impact on self-esteem (Kramer \& Winter, 2008).

The study of Wilcox \& Stephen (2012) reports that social media are used by hundreds of millions of people daily, but little is known about their impact on behaviour. In five experiments, the authors demonstrate that the use of the social network boosts self-esteem on users who focus on close friends (i.e. strong bonds) while browsing their social network. However, while self-esteem is reinforced and temporarily boosted, the same does not apply for their self-control, which decreases, especially amongst the users which maintain strong bonds through a social network. Also, the authors present data suggesting that the more frequent use of the social network is connected with a higher body mass index and higher levels of credit card debts for people with stronger bonds with their social networks (Wilcox \& Stephen, 2012).

The study of Gangadharbatla (2008) examined the effect of the students' self-esteem level, their need to belong somewhere, their need for knowledge, and collective self-esteem for their attitude towards social media. The Internet's self-efficiency, the need to belong somewhere and the collective self-esteem had a positive correlation with the attitudes towards social media. Also, the attitude towards social media correlates with the relation of eagerness to become a member of them. Self-efficiency showed online, the need to belong somewhere and collective self-esteem are some of the characteristics of the general eagerness to attend social networks (Gangadharbatla, 2008).

The study of Mehdizadeh (2010), which examined 100 users of Facebook, tried to detect how narcissism and self-esteem are reflected in it. The analyses revealed that people with high levels of narcissism and low levels of self-esteem are connected with a higher online activity, as well as with some content of self-promotion. Finally, it was found out that different genders affect the type of advertising material presented by some individual Facebook users (Mehdizadeh, 2010).

Vogel et al. (2014) conducted a double research on social media, claiming that 
they offer numerous chances of social comparison. Aim of the surveys was to examine the impacts of chronic and temporary exposure to social information, in comparison with self-esteem. By using a correlating approach, the first survey examined to what extent self-esteem and the low or poor user profile is related with the frequency of the use of Facebook. Indeed, results showed that participants who were using Facebook more often had a lower self-esteem and that was due to the increased exposure to social comparisons in the social media. By using an experimental approach, the second survey studied the impact of temporary exposures to social networks' profiles, in relation to the degree of self-esteem and relevant self-assessments. The results revealed that the participants' degree of self-esteem and the relevant self-assessments were lower when the profile of the targeted person included comparison information upwards (e.g. a high activity social network, healthy habits) rather than when the profile of that particular person contained comparison information downwards (e.g. a low activity social network, unhealthy habits) (Vogel et al., 2014).

The study of Andreassen et al. (2017) states that social networking sites have become an increasingly popular recreational activity over the last decade. Even though the use of social media is not problematical for most people, a small number of users appear to use them excessively or even obsessively. The main goal of their study was to examine the correlation between addictive use of social media, narcissism and self-esteem. In the survey, a sample of 23.532 Norwegians who completed three scales related with the dimensions examined was used. Even though most impact degrees were rather mediocre, findings supported the notion of the addictive use of social media, which reflect the need to feed the ego (i.e. narcissistic personality characteristics) combined with an effort to prevent a negative self-esteem (Andreassen et al., 2017).

The study of Woods \& Scott (2016) examined to which extent the use of social media affects sleep quality, self-esteem, stress and depression, among 467 teenagers. The total use of social media, their use during the night, the emotional investments on social media, the sleep quality, the self-esteem and the levels of stress and depressions were measured. The teenagers who used more social media - in total and at night - and those who had invested more into them, presented poor sleep quality, lower self-esteem, and higher levels of stress and depression (Woods \& Scott, 2016).

Gonzales \& Hancock (2011) made opposite propositions to control the impact of Facebook exposure on self-esteem. The objective self-consciousness from social psychology and the transpersonal model of communication through computers were used to support that Facebook would either lessen or boost self-esteem respectively. The findings demonstrated that, contrary to the previous studies on objective self-consciousness, the knowledge of one's self boosts self-esteem and does not lower it through the display of the personal profile on Facebook. The participants who updated their profiles and saw their profiles during the experiment reported also higher self-esteem, which offers extra support to the transpersonal model. Those findings show that selective self-projection 
on social media, leading in intensification of the relationship, also affect the impressions of the self (Gonzales \& Hancock, 2011).

The study of Skues et al. (2012), examined the relationship among particular characteristics (neuroticism, extroversion, tolerance, self-esteem, loneliness and narcissism) when using Facebook. The participants were 393 first year psychology students of a middle-sized University of Australia, who filled in an electronic questionnaire. The results indicated that students with higher tolerance levels spend more time on Facebook and have more friends. It is interesting that students with higher loneliness levels reported they have more friends on Facebook. Extroversion, neuroticism, self-esteem and narcissism had no important correlations with the use of Facebook. The conclusion was that students with greater socialisation use Facebook to connect with others in order to discuss a wide range of topics, whilst lonely students use Facebook to offset the lack of realistic relations (Skues et al., 2012).

Finally, the survey of Burke et al. (2011) examined how Facebook affects the social capital depending on individual differences among users, including social interaction and self-esteem skills. Longitudinal surveys which matched with the servers recording data of 415 Facebook users revealed that receiving messages from friends is related with the increase of the social capital, but it appears that other uses are not correlated. Nonetheless, the use of Facebook for the passive news consumption helps people with lower social flexibility to draw value through the communication with others (Burke et al., 2011).

The findings about the relation between self-esteem and social networks are still contradictory. Some studies detected a positive impact of social media on self-esteem, whereas other ones did not detect any impact. This means that, in order to illustrate clearly whether the area of self-esteem-and this of teenagers, in particular-is affected by the use of social networks, more surveys should be conducted, investigating additional characteristics of the users. Therefore, our effort to examine the correlation between teenagers' self-esteem and the use of Facebook contributes to the scientific knowledge.

\section{Research Methodology}

The survey was conducted in January 2018 at the Ziridis private school. The reason why we chose a private school is that students come from a good social, financial and educational level, and they have not been influenced severely by Greece's financial crisis. Therefore, they would have the chance to own PCs, tablets, smartphones and Internet connection. The participation in the survey was voluntary.

\subsection{Research Aim, Objectives and Hypotheses}

Goal of the survey was to examine Facebook influence in teenagers' self-esteem, whether teenage students use Facebook safely and whether the time spent by teenaged students on Facebook is against their personal relationships or other basic daily habits and obligations. 
1) To investigate whether teenagers' self-esteem is influenced by their activity on Facebook we asked the following research questions:

a) Whether students' self-esteem is correlated with the number of friends/ followers on Facebook

b) Whether students' self-esteem is correlated with the number of "likes" they have on their latest profile pictures.

c) Whether students' self-esteem is correlated with the time spent on using the Facebook application

d) Whether students' self-esteem is correlated with the number of posts they make on Facebook

e) Whether students' self-esteem is correlated with the use or not of $\operatorname{tags}^{1}$ of people who do not appear on their photos.

f) Whether students' self-esteem is correlated with the display of personal information on Facebook.

Specific targets were:

2) To investigate whether teenage students use Facebook safely we asked the following research questions:

a) To what extent they display personal information on Facebook.

b) What percentage of their posts can be seen by everyone or only by friends?

c) To what extent they allow getting "likes" for anything posted by anyone or only by friends.

3) To examine whether the time spent by teenaged students on Facebook is against their personal relationships or other basic daily habits and obligations we asked the following research questions:

a) Whether they use daily social networks and how much time they spend on them.

b) Whether they get out of their houses and how often.

c) If, in order to find enough time to use social networks, they have reduced the time spent on studying, sleeping/resting, recreation, contacting friends, sports

\subsection{Participants: Demographic and Social Features of the Sample}

71 students of the first grade of High School (Greek Lyceum), aged 16, participated in the study. Most participants were boys $62.9 \%$ and $37.1 \%$ were girls.

The average grades during the previous school year were $17.1 \pm 1.6$, the lowest grade being 11.7 and the highest $20.21 .4 \%$ had grades up to $16.9 \%, 52.9 \%$ up to $18.9 \%$ and $25.7 \%$ over 19.

\subsection{Research Tools}

The measurement of teenagers' self-esteem was carried out using the psychometric tool PATEM IV, which is the Greek version of the questionnaire The ${ }^{1}$ When you tag someone, you create a link to their profiles. The post where you tag the person may appear in that person's profile. For instance, you may tag someone in a photo to show who is in that photo or post a status update and say who you are with. 
Self-Perception Profile for Adolescents (Harter, 1988) and has been adjusted in

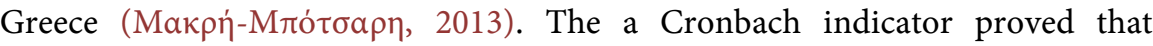
PATEM IV questionnaire has good reliability and the questions vary from 0.906 up to 0.880 . The mean of PATEM IV questionnaire was $2.8 \pm 0.3$, with the lowest value being 2.02 and the highest one 3.57 . The PATEM scales are:

1) General school performance

2) Relationships with peers

3) Relationships with parents

4) Math skills

5) Sports skills

6) Physical appearance

7) Job-readiness

8) Skills in language courses

9) Emotional relationships with the opposite sex

10) Conduct/behaviour

11) Close friends

12) Self-esteem

The form of the questions is statements of binary format to minimise socially desired answers. The students filled in the questionnaire inside the classroom in the presence of the researcher who encouraged the students to read through the instructions carefully and afterwards they studied a random question together.

In the PATEM IV questionnaire, in order to investigate whether there is a correlation between self-esteem and the activity of teenager's on Facebook, we added questions related to Facebook functions regarding acceptance and popularity. The questions were about the number of friends they have, the "likes" they receive for their photos, the "tags" they are making and the number of posts. We also added questions about the exposure of personal information in order to find out whether they use Facebook safely or they get carried away and expose their personal information in order to increase their acceptance or popularity, as well as questions to examine how much time teenagers spend on Facebook and to what extent this affects their interpersonal relationships and their activities or is related with their self-esteem. We finally added socio-demographic questions.

\subsection{Analysis}

SPSS 25 analysis was used for the analysis and processing of the research data.Mean values and standard deviation were used for the description of quantitative variables. Percentages were used for the description of qualitative variables. Person correlation was used to identify the relationship between the studied variables. Also, differences between variables were analyzed using student's t-test and analysis of variances.

\section{Statistical Data Analysis and Results}

We found out the following after the descriptive analysis of the data: 
In the question "how many friends/followers do you have on Facebook?", the mean of the number of friends was 750.9 ( \pm 688 ), the mode being 500 friends, varying between 10 and 3000 friends. Moreover, the majority of the sample $28.6 \%$ had over 901 friends, $22.9 \%$ had 301 - 500 friends, $15.7 \%$ had $501-700$, $12.9 \%$ had $101-300$ and the same percentage had less than 100 friends and finally $7.1 \%$ had 701 - 900 friends.

$55.7 \%$ of the participants stated that they accept friend requests only by people they know. $40 \%$ answered they accept also strangers in case they have mutual friends and $4.3 \%$ answered that they accept anyone's friend requests.

In the questions "how many "likes" approximately did your two latest profile pictures have?", the mean was $19.0 \pm 154$. The lowest value of likes was 0 and the highest $750.50 \%$ of the persons have 101 to 300 likes, 31.4\% below 100 likes, $12.9 \% 301$ to 500 likes and $5.7 \%$ more than 500 likes in their two latest profile pictures.

$51.6 \%$ of the sample answered they "tag" more people than those appearing on the photos.

In the question: "do you share personal information?", the majority of the sample, $81.4 \%$ answered negatively and only $18.6 \%$ answered affirmatively in that particular question.

The mean of the photos posted was $22 \pm 41$, varying between 0 and 300 . $55.7 \%$ ) has uploaded up to 10 photos, $18.6 \% 11$ to $20,12.9 \% 21$ to $30,1.4 \% 31$ to $40,2.9 \% 41$ to 50 and $8.6 \%$ more than 51 photos.

$72.9 \%$ answered that only friends can see their posts, while $27.1 \%$ answered that everyone can see their posts.

The majority of the sample $75.7 \%$ answered that only friends may "like" their posts, while $24.3 \%$ answered that everyone may "like" their posts.

In the question: "if one post does not get enough "likes", do you delete it?", $90 \%$ answered negatively and only $10 \%$ answered affirmatively.

The majority of the sample $87.1 \%$ answered that they use social networks on a daily basis, while $12.9 \%$ answered negatively.

$35.7 \%$ of the sample answered that they spend two hours on social networks, $22.9 \%$ answered 30 minutes, $21.4 \%$ over two hours and $20 \%$ one hour.

$62.9 \%$ answered that they go out 2 - 3 times a week, $28.6 \%$ once a week and $8.6 \% 5$ - 6 times a week.

$34.7 \%$ of the students answered that, in order to save time for social networks, they have reduced the time spent for sleeping and resting, $18.6 \%$ answered that they have reduced the time spent for studying, $8.6 \%$ answered that they have reduced the time spent for sports and $2.9 \%$ answered that they have reduced the time spent for recreation and contact with friends.

In the question: "do you believe that social networks are beneficial for you or not?", $84.3 \%$ answered affirmatively and $15.7 \%$ negatively.

As for the sub-scales of PATEM IV, the highest values were received by the scale "close friends" and the scale "self-esteem", whereas the lowest ones were received by the "math skills" and "skills in language courses" (Table 1). 
Table 1. Sub-scales of the PATEM IV questionnaire.

\begin{tabular}{ccccc}
\hline & Mean & $\begin{array}{c}\text { Standard } \\
\text { deviation }\end{array}$ & $\begin{array}{c}\text { Minimum } \\
\text { value }\end{array}$ & $\begin{array}{c}\text { Maximum } \\
\text { value }\end{array}$ \\
\hline General school performance & 2.91 & 0.67 & 1.40 & 4.00 \\
Relationships with peers & 2.95 & 0.62 & 1.60 & 4.00 \\
Relationships with the parents & 2.96 & 0.68 & 1.00 & 4.00 \\
Math skills & 2.43 & 0.85 & 1.00 & 4.00 \\
Sports skills & 2.98 & 0.80 & 1.00 & 4.00 \\
Physical appearance & 2.89 & 0.86 & 1.40 & 4.00 \\
Self-esteem & 3.05 & 0.58 & 1.30 & 4.00 \\
Job-readiness & 2.98 & 0.56 & 1.40 & 4.00 \\
Skills in language courses & 2.35 & 0.87 & 1.00 & 4.00 \\
Emotional relationships with & 2.79 & 0.72 & 1.00 & 4.00 \\
the opposite sex & & & & 4.00 \\
Conduct/behaviour & 2.88 & 0.69 & 1.20 & 4.00 \\
Close friends & 3.42 & 0.64 & 1.60 & \\
\hline
\end{tabular}

The difference between sex and PATEM IV $(p=0.0 .26)$ was statistically significant. The mean for boys was 2.9 while for girls it was 2.7 . The average grades awarded was not correlated with the PATEM IV scale.

The number of friends/followers on Facebook was not correlated with the PATEM IV scale. A positive correlation between the sub-scale physical appearance and how many friends the participants have on Facebook was found. The higher the sub-scale of the self-perception questionnaire about physical appearance, the higher the number of friends. The acceptance of a friend request was not found to be statistically important as for the PATEM IV scale $(p=0742)$. The number of "likes" was not correlated with the PATEM IV scale. A positive correlation between the sub-scale "relationships with peers" and "emotional relationships with the opposite sex" and the number of likes on the two latest profile pictures was found. The higher the self-perception of the above mentioned two sub-scales, the higher the number of "likes". The number of photos uploaded was not correlated with the PATEM IV scale. A negative correlation was found between the number of photos uploaded by the participants and the sub-scale "close friends". The higher the self-perception of the sub-scale "close friends", the lower the number of photos (Table 2).

Table 2. Correlations between questions and PATEM IV scale.

\begin{tabular}{|c|c|c|}
\hline & & $\begin{array}{l}\text { How many friends/followers do you have } \\
\text { on Facebook? }\end{array}$ \\
\hline & Pearson Correlation & -0.048 \\
\hline \multirow[t]{3}{*}{ PATEM IV } & Sig. (2-tailed) & 0.691 \\
\hline & $\mathrm{N}$ & 70 \\
\hline & & $\begin{array}{l}\text { How many friends/followers do you have on } \\
\qquad \text { Facebook? }\end{array}$ \\
\hline
\end{tabular}




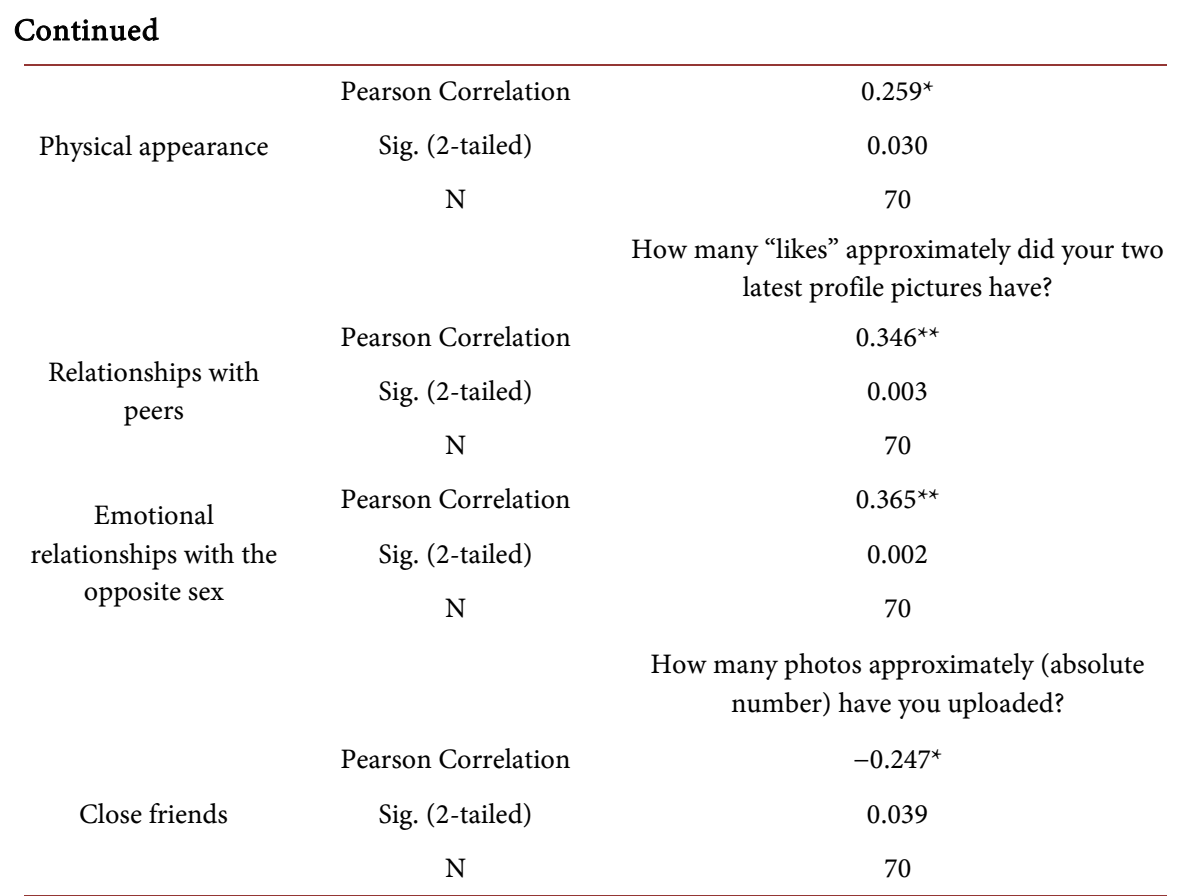

The question whether the person "tags" more people than those appearing on the photos was not found to have statistically significant differences as for the PATEM IV scale $(p=0.108)$. Whether the person shares personal information was not found to have statistically significant differences as for the PATEM IV scale ( $p=0.246)$. The question "who can see your posts (only friends-everyone)?" was not found to have a statistically significant difference as for the PATEM IV scale $(p=0.829)$. The question "who can 'like' your posts?" was not found to have a statistically significant difference as for the PATEM IV scale $(p=0.768)$. The question "do you delete posts if they do not get enough 'likes'?" was not found to have a statistically significant difference as for the PATEM IV scale ( $p=$ 0.480 ). The daily use of social networks was not found to have a statistically significant difference as for the PATEM IV scale $(p=0.946)$. The time spent daily on social networks by the participants was not found to have a statistically significant difference as for the PATEM IV scale $(p=0.732)$. The number of times the participants go out weekly was not found to have a statistically significant difference as for the PATEM IV scale $(p=0.067)$. The reduction of time spent on studying due to social networks was not found to have a statistically significant difference as for the PATEM IV scale $(p=0.979)$. The reduction of time spent on sleeping/resting was not found either to have a statistically significant difference as for the PATEM IV scale $(p=0.075)$. The reduction of the time spent on recreation due to social networks has not been found to have a statistically significant difference as for the PATEM IV scale $(p=0.223)$. The same goes for the reduction of the time spent with friends, it was not found to have a statistically significant difference as for the PATEM IV scale $(p=0.052)$. The reduction of the time spent on sports has not been found to have a statistically significant difference as for the PATEM IV scale $(p=0.251)$. Also, the belief of the 
participants about whether social networks are beneficial or not was not found to have a statistically significant difference as for the PATEM IV scale ( $p=$ $0.102)$.

Statically significant differences were found:

1) In the sub-scale "close friends" and whether the participants share personal information $(p=0.038)$. Participants with higher mean in the sub-scale close friends tend to share personal information.

2 ) In the sub-scale "Relationships with peers" and whether participants use social networks on a daily basis $(p=0.029)$. Participants with a higher mean in the sub-scale "Relationships with peers" tend to use social networks on a daily basis.

3) In the sub-scale self-esteem and whether the social networks have reduced the time spent on sleeping/resting $(p=0.014)$. Participants with a higher mean in the sub-scale "self-esteem", tend to not having reduced the time spent on sleeping/resting due to the use of social networks.

4) In the sub-scale "close friends" and whether the social networks have reduced the time spent on contacting friends $(p=0.021)$. Participants with a higher mean in the sub-scale "close friends", tend to not having reduced the time spent with friends due to the use of social networks.

5) In the sub-scale "relationships with peers" and the sub-scale "emotional relationships with the opposite sex" about whether the participants believe that social networks are beneficial ( $p=0.001$ and $p=0.001$ respectively). Participants with a higher mean in the above sub-scales tend to believe that social networks are beneficial (Table 3 ).

Table 3. Statistically significant differences between sub-scales PATEM IV and questions.

\begin{tabular}{|c|c|c|c|}
\hline & Do you share personal information? & Mean & Standard deviation \\
\hline \multirow{2}{*}{ Close friends } & Yes & 3.75 & 0.38 \\
\hline & No & 3.35 & 0.66 \\
\hline \multirow{4}{*}{ Relationships with peers } & $\begin{array}{l}\text { Do you use social networks on a daily } \\
\text { basis? }\end{array}$ & Mean & Standard deviation \\
\hline & Yes & 3.01 & 0.60 \\
\hline & No & 2.53 & 0.63 \\
\hline & Sleeping/resting & Mean & Standard deviation \\
\hline \multirow{2}{*}{ Self-esteem } & Yes & 2.82 & 0.63 \\
\hline & No & 3.17 & 0.52 \\
\hline \multirow{4}{*}{ Close friends } & Contact with friends & Mean & Standard deviation \\
\hline & Yes & 2.40 & 0.85 \\
\hline & No & 3.45 & 0.62 \\
\hline & $\begin{array}{l}\text { Do you believe that social networks } \\
\text { benefit you or not? }\end{array}$ & Mean & Standard deviation \\
\hline \multirow{2}{*}{ Relationships with peers } & Yes & 3.06 & 0.55 \\
\hline & No & 2.38 & 0.66 \\
\hline \multirow{2}{*}{$\begin{array}{l}\text { Emotional relationships } \\
\text { with the opposite sex }\end{array}$} & Yes & 2.92 & 0.66 \\
\hline & No & 2.11 & 0.65 \\
\hline
\end{tabular}


Finally, a difference was found in the sub-scale "emotional relationships with the opposite sex" and the frequency of going out weekly $(p=0.001)$. Participants with a higher mean in the sub-scale "emotional relationships with the opposite sex" tend go out more times weekly (Table 4).

Table 4. Correlation between emotional relationships with the opposite sex and how many times they go out.

\begin{tabular}{ccc}
\hline \multicolumn{3}{c}{ Emotional relationships with the opposite sex } \\
\hline How many times a week do you go out? & Mean & Standard deviation \\
\hline 1 time & 2.31 & 0.69 \\
2 - 3 times & 2.95 & 0.64 \\
$4-5$ times & 3.23 & 0.71 \\
\hline
\end{tabular}

\section{Discussion}

The results of the research regarding our research questions about whether the degree of popularity and acceptance on Facebook is correlated with teenagers' self-esteem showed that:

1) There is no significant correlation between teenagers' self-esteem and the number of friends-followers on Facebook.

2) There is no significant correlation between teenagers' self-esteem and the number of "likes" on their latest profile pictures.

3) There is no significant correlation between teenagers' self-esteem and the time spent using Facebook.

4) There is no significant correlation between teenagers' self-esteem and the number of posts they make on Facebook.

5) There is no significant correlation between teenagers' self-esteem and the use of "tag" or not of people that do not appear on their photos.

6) There is no significant correlation between teenagers' self-esteem and the display of personal information on Facebook.

According to our findings, it appears that self-esteem is not correlated with the frequency the users use Facebook or their level of acceptance or popularity. Similar findings have been found in researches of adults (Kramer \& Winter, 2008; Skues et al., 2012). On the contrary, other surveys of teenagers and adults have found a correlation between social networks and self-esteem (Gallagher, 2017; Valkenburg et al., 2006; Kraut et al., 1998). Therefore, more research is needed.

The number of "likes" is positively correlated with the relationships with peers and the opposite sex. It appears that, through social media, teenagers seek recognition and the creation of relationships. Other researches have concluded that teenagers use social networks to create strong and healthy relationships, too (Ellison, Steinfield, \& Lampe, 2007; Barker, 2009). In fact, they share more personal information when they feel that they have close friends and they post fewer photos. The close bonds they develop give them the feeling that the environment 
is safe and that they can share personal information. The teenagers who have developed close relationships on social media seem to use them mostly for communication and maintenance of the relationships and less for self-projection.

The physical appearance is positively correlated with the number of friends on Facebook. The importance of physical appearance on teenagers' self-esteem is supported by other researches as well (Harter, 2000; Eugene W. Mathes \& Arnold Kahn, 2010; Gallagher, 2017). The number of "likes" is positively correlated with the relationships with the opposite sex. Teenagers with more "likes" on their profile pictures have developed better relationships with the opposite sex. It appears that "likes" make teenager's feel more comfortable about communicating and making relationships with persons of the opposite sex.

The attention teenagers pay on their appearance is confirmed also by the fact that slightly more than half of the participants in the study try to achieve more displays of their photos by "tagging" more persons than those appearing in the photo. We could assume that they pursue in this way a higher number of "likes" on their photos. It seems that they feel the need to be accepted and socially recognized by others and they use all Facebook's tools to increase the number of "likes" received. Even though our research did not show a significant correlation between self-esteem and "likes" and "tags", we believe that it is a matter worth investigating more in the future.

Furthermore, the behaviour of $90 \%$ of the teenagers of the sample is encouraging, since they state that they do not delete a post if it does not receive enough "likes". It seems that teenagers support their choices, even when they are not widely accepted.

As for the level of safe use of Facebook by the teenagers of the sample, it appears that the majority of them are aware of the dangers of the Internet and the protection of their personal data. The awareness of the sample's teenagers about the dangers of Facebook is also supported by the fact that $81.4 \%$ state that they do not share personal information on Facebook. 95\% do not add as friends on Facebook total strangers and $72.9 \%$ share their posts only with friends. Also, $55.7 \%$ have uploaded up to 10 photos on Facebook. It appears that the information and constant awareness about the dangers of the exposure on Facebook has helped teenagers to understand that the display of personal information, details of their everyday lives and preferences to strangers makes them vulnerable and potential victims of exploitation. The results of our survey propose that teenagers understand the dangers of Facebook and use it safely.

Most $57.1 \%$ teenagers of the sample, and particularly those who pay much attention to the relationships with their peers, use social networks daily, at least two hours a day. It appears that we find ourselves in a new era, where social networks play a significant role in the lives of teenagers. This must trouble us, since studies show that the frequency of the use of Facebook is correlated with depression symptoms and reduction of well-being (Feinstein et al., 2013). 
$70.9 \%$ of the teenagers of the sample go out at least twice a week. It seems that teenagers do not stay at home using exclusively social networks, but they find time to go out and develop interpersonal relationships. Our study found out that those who prioritise relationships go out more.

$53 \%$ of the teenagers sacrifice their sleep and studying in order to find time and use social networks. Woods \& Scott (2016) found poor sleep quality among people who use frequently social networks and who have invested emotionally in them. It is remarkable that people with high self-esteem have not reduced the time spent on sleeping and resting due to the use of social networks. It is pointed out that the sacrifice of the sleep is worrying and must be further investigated. Sleep is one of man's basic needs, vital for one's proper development. During adolescence, teenagers need more resting and sleeping due to hormonal and physical changes. Therefore, insufficient sleep may cause development problems to teenagers, as well as physical fatigue, leading to their inability to meet their obligations.

A significant difference was found in the sub-scale "close friends" and whether the use of social networks has reduced the time spent with friends $(p=0.021)$. Participants with a higher mean in the sub-scale "close friends", tend to not having reduced the time spent with friends due to the use of social networks. It appears that teenagers with intimate friendships prefer people-to-people contact with their friends rather than communication though social networks. Our research confirms the need of teenagers to belong to a group, as well as the importance of the relationship with peers during adolescence, in order to build self-esteem.

Finally, in general, the majority $84.3 \%$ of the teenagers who took part in the survey believe that social media are beneficial for the users. In fact, there is a positive correlation between the usefulness of the social media and teenagers who emphasise on the relationships with peers and the opposite sex. It appears they have established close links and relationships and they feel familiar and safe with the use of Facebook.

\section{Conclusions}

Our research did not find a positive correlation between the use of Facebook and self-esteem of the teenagers who participated in the survey, but other significant findings emerged. Firstly, it reinforces the view that the use of social networks has become an important and daily part of teenagers' lives. The majority of teenagers seem to limit their use within communities of acquaintances and friends and avoid exposure to strangers. Teenagers appear to participate in social media mainly in order to establish or maintain relationships with close friends, peers and the opposite sex. We can conclude that they make prudent and safe use. Facebook seems to help establish relationships and particularly with the opposite sex. It is worth mentioning that their interpersonal relationships and contacts have not been limited due to social networks. It is highlighted that the accep- 
tance of their appearance is correlated with the number of friends. It appears that the higher number of Facebook friends makes them feel better for their appearance, maybe this is the reason why more than half of the participating teenagers "tag", in order to increase their friends. Finally, we must feel concerned about the fact that a high percentage sacrifices time for sleeping to use social networks.

\section{Limitations}

The limitations of the research are the lack of diversity and the small sample size. The sample was 71 teenagers of the $1^{\text {st }}$ class of High School (Greek Lyceum) of a private school situated in Athens. Our results would be more accurate if the sample were larger. Also, all students came from a private school and from the area of Athens, their families had a social, educational and financial status higher than the average of a Greek family, and this may explain the fact that their self-esteem was above average. Our results would be more accurate if our sample included students from other areas of Greeks, of different social, educational and financial statuses.

\section{Recommendation for Future Research}

Because researches conducted regarding the impact of social networks on teenagers' self-esteem are contradictory, further research is required, examining more parameters in a larger sample.

It would be interesting to conduct researches-and they would help clarify the impact of social networks on self-esteem-examining the individual forms of social comparisons within the social networks and their impact on the self-esteem of teenagers and adults.

Given that one female student of our research was not member of a social network and she was found to have the lowest self-esteem amongst the teenagers of our sample, we reckon that a longitudinal study that would primarily measure the self-esteem of teenagers who are not members of a social network and secondly measure it again after them becoming members, would be useful and could help answer the question whether the use of social networks by teenagers is preferable than their non-use and strengthens their self-esteem.

Finally, more researches need to be conducted that consider cases in which teenagers feel embarrassed or undergo bullying through their use of social media. Those could protect adolescents and provide some suggestions on the correct and safe use social media.

\section{References}

Al-Jubayer, S. M. (2013). The Use of Social Networking Sites among Teenagers: A Study of Face-Book in Phaka City. Journal of International Social Issues, 2, 35-44.

Amichai-Hamburger, Y., \& Vinitzky, G. (2010). Social Network Use and Personality. Computers in Human Behavior, 26, 1289-1295.

https://doi.org/10.1016/j.chb.2010.03.018 
Andreassen, C. S., Pallesen, S., \& Griffiths, M. D. (2017). The Relationship between Addictive Use of Social Media, Narcissism, and Self-Esteem: Findings from a Large National Survey. Addictive Behaviors, 64, 287-293. https://doi.org/10.1016/j.addbeh.2016.03.006

Aspinwall, L. G. (1997). Future-Oriented Aspects of Social Comparisons: A Framework for Studying Health-Related Comparison Activity. In B. P. Buunk, \& F. X. Gibbons (Eds.), Health, Coping, and Well-Being: Perspectives from Social Comparison Theory (pp. 125-166). Mahwah, NJ: Erlbaum.

Barker, V. (2009). Older Adolescents' Motivations for Social Network Site Use: The Influence of Gender, Group Identity, and Collective Self-Esteem. Cyberpsychology \& Behavior, 12, 209-213. https://doi.org/10.1089/cpb.2008.0228

Barry, T. C., Grafeman, J. S., Adler, K. K., \& Pickard, D. J. (2007). The Relations among Narcissism, Self-Esteem, and Delinquency in a Sample of At-Risk Adolescents. Journal of Adolescence, 30, 933-942. https://doi.org/10.1016/j.adolescence.2006.12.003

Burke, M., Kraut, R., \& Marlow, C. (2011). Social Capital on Facebook: Differentiating Uses and Users. In Proceedings of the 2011 Annual Conference on Human Factors in Computing Systems (pp. 571-580). New York, NY: ACM.

https://doi.org/10.1145/1978942.1979023

Caplan, S. E. (2003). Preference for Online Social Interaction: A Theory of Problematic Internet Use and Psychosocial Well-Being. Communication Research, 30, 625-648.

https://doi.org/10.1177/0093650203257842

Coopersmith, S. (1967). The Antecedents of Self-Esteem. San Francisco, CA: W. H.

Ellison, N., Steinfield, C., \& Lampe, C. (2007). The Benefits of Facebook "Friends": Social Capital and College Students' Use of Online Social Network Sites. Journal of Computer-Mediated Communication, 12, 1143-1168.

https://doi.org/10.1111/j.1083-6101.2007.00367.x

Emler, N. (2001). Self Esteem: The Costs and Causes of Low Self Worth. York: York Publishing Services.

Feinstein, B. A., Hershenberg, R., Bhatia, V., Latack, J. A., Meuwly, N., \& Davila, J. (2013). Negative Social Comparison on Facebook and Depressive Symptoms: Rumination as a Mechanism. Psychology of Popular Media Culture, 2, 161-170.

https://doi.org/10.1037/a0033111

Forest, A. L., \& Wood, J. V. (2012). When Social Networking Is Not Working: Individuals with Low Self-Esteem Recognize But Do Not Reap the Benefits of Self-Disclosure on Facebook. Psychological Science, 23, 295-302. https://doi.org/10.1177/0956797611429709

Gallagher, M. S. (2017). The Influence of Social Media on Teens' Self-Esteem. MA Thesis, Stratford, NJ: Department of Psychology, College of Science and Mathematics, Rowan University. https://soic.iupui.edu/files/Thesis_content_example2.pdf

Gangadharbatla, H. (2008). Facebook Me: Collective Self-Esteem, Need to Belong, and Internet Self-Efficacy as Predictors of the iGeneration's Attitudes toward Social Networking Sites. Journal of Interactive Advertising, 8, 5-15.

https://doi.org/10.1080/15252019.2008.10722138

Gonzales, A. L., \& Hancock, J. T. (2011). Mirror, Mirror on My Facebook Wall: Effects of Exposure to Facebook on Self-Esteem. Cyberpsychology, Behavior, and Social Networking, 14, 79-83. https://doi.org/10.1089/cyber.2009.0411

Haferkamp, N., \& Kramer, N. C. (2011). Social Comparison 2.0: Examining the Effects of Online Profiles on Social-Networking Sites. Cyberpsychology Behavior, and Social 
Networking, 14, 309-314. https://doi.org/10.1089/cyber.2010.0120

Harter, S. (1988). Manual for the Self-Perception Profile for Adolescents. Denver, CO: University of Denver Press.

Harter, S. (1999). The Construction of the Self: A Developmental Perspective. New York, NY: Guilford Press.

Harter, S. (2000). Is Self-Esteem Only Skin-Deep? The Inextricable Link between Physical Appearance and Self-Esteem. Reclaiming Children and Youth; Bloomington, 9, 133-138.

Hetherton, T. F., \& Polivy, J. (1991). Development and Validation of a Scale for Measuring State Self-Esteem. Journal of Personality and Social Psychology, 60, 895-910. https://doi.org/10.1037/0022-3514.60.6.895

Huang, C. (2010). Internet Use and Psychological Well-Being: A Meta-Analysis. Cyberpsychology, Behavior, and Social Networking, 13, 241-249. https://doi.org/10.1089/cyber.2009.0217

Ivcevic, Z., \& Ambady, N. (2012). Personality Impressions from Identity Claims on Facebook. Psychology of Popular Media Culture, 1, 38-45.

https://doi.org/10.1037/a0027329

James, W. (1890). The Principles of Psychology. New York, NY: Holt.

Kramer, N. C., \& Winter, S. (2008). Impression Management 2.0: The Relationship of Self-Esteem, Extraversion, Self-Efficacy, and Self-Presentation within Social Networking Sites. Journal of Media Psychology: Theories, Methods, and Applications, 20, 106.

Kraut, R., Patterson, M., Lundmark, V., Kiesler, S., Mukopadhyay, T., \& Scherlis, W. (1998). Internet Paradox: A Social Technology That Reduces Social Involvement and Psychological Well-Being? American Psychologist, 53, 1017-1031. https://doi.org/10.1037/0003-066X.53.9.1017

Labrague, L. (2014). Facebook Use and Adolescents' Emotional States of Depression, Anxiety, and Stress. Health Science Journal, 8, 80-89.

Lan, W., \& Lanthier, R. (2003). Changes in Students' Academic Performance and Perceptions of School and Self before Dropping out of Schools. Journal of Education for Students Placed at Risk, 8, 309-332. https://doi.org/10.1207/S15327671ESPR0803_2

Lockwood, P., \& Kunda, Z. (1997). Superstars and Me: Predicting the Impact of Role Models on the Self. Journal of Personality and Social Psychology, 73, 91-103. https://doi.org/10.1037/0022-3514.73.1.91

Marsh, H. W., \& Parker, J. W. (1984). Determinants of Student Self-Concept: Is It Better to Be a Relatively Large Fish in a Small Pond Even If You don't Learn to Swim as Well? Journal of Personality and Social Psychology, 47, 213-231.

Mathes, E. W., \& Kahn, A. (2010). Physical Attractiveness, Happiness, Neuroticism, and Self-Esteem. The Journal of Psychology, 90, 27-30.

Mehdizadeh, S. (2010). Self-Presentation 2.0: Narcissism and Self-Esteem on Facebook. Cyberpsychology, Behavior, and Social Networking, 13, 357-364.

Pounders, K., Kowalczyk, M. C., \& Stowers, K. (2016). Insight into the Motivation of Selfie Postings: Impression Management and Self-Esteem. European Journal of Marketing, 50, 1879-1892. https://doi.org/10.1108/EJM-07-2015-0502

Reinherz, H. Z., Giaconia, R. M., \& Pakiz, B. (1993). Psychosocial Risks for Major Depression in Late Adolescence: A Longitudinal Community Study. Journal of American Academy Child Adolescence Psychiatry, 32, 1155-1163.

https://doi.org/10.1097/00004583-199311000-00007 
Rideout, V. J., Foehr, U. G., \& Roberts, D. F. (2010). Generation M: Media in the Lives of 8- to 18-Year-Olds. Henry J. Kaiser Family Foundation. http://www.eric.ed.gov/PDFS/ED527859.pdf

Roberts, J. E., Gotlib, I. H., \& Kassel, J. D. (1996). Adult Attachment Security and Symptoms of Depression: The Mediating Roles of Dysfunctional Attitudes and Low Self-Esteem. Journal of Personality and Social Psychology, 70, 310-320. https://doi.org/10.1037/0022-3514.70.2.310

Rogers, C. R. (1959). A Theory of Therapy, Personality, and Interpersonal Relationships, as Developed in the Client-Centered Framework. New York, NY: McGraw-Hill.

Rosenberg, M. (1965). Society and Adolescent Self-Image. Princeton, NJ: Princeton University Press. https://doi.org/10.1515/9781400876136

Rumberger, R. W. (1995). Dropping out of Middle School: A Multilevel Analysis of Students and Schools. American Educational Research Journal, 32, 583-625. https://doi.org/10.3102/00028312032003583

Scott, C. G., Murray, G. C., Mertens, C., \& Dustin, E. R. (1996). Student Self-Esteem and the School System: Perceptions and Implications. The Journal of Educational Research, 89, 286-293. https://doi.org/10.1080/00220671.1996.9941330

Shapira, N., Barak, A., \& Gal, I. (2007). Promoting Older Adults' Well-Being through Internet Training and Use. Aging \& Mental Health, 11, 477-484.

Shaw, L. H., \& Gant, L. M. (2002). In Defense of the Internet: The Relationship between Internet Communication and Depression, Loneliness, Self-Esteem, and Perceived Social Support. Cyberpsychology \& Behavior, 5, 157-171.

https://doi.org/10.1089/109493102753770552

Skues, J. L., Williams, B., \& Wise, L. (2012). The Effects of Personality Traits, Self-Esteem, Loneliness, and Narcissism on Facebook Use among University Students. Computers in Human Behavior, 28, 2414-2419. https://doi.org/10.1016/j.chb.2012.07.012

Steinfield, C., Ellison, N. B., \& Lampe, C. (2008). Social Capital, Self-Esteem, and Use of Online Social Network Sites: A Longitudinal Analysis. Journal of Applied Developmental Psychology, 29, 434-445. https://doi.org/10.1016/j.appdev.2008.07.002

Tajfel, H. (1978). Social Categorization, Social Identity and Social Comparison. In H. Tajfel (Ed.), Differentiation between Social Groups: Studies in the Social Psychology of Intergroup Relations (pp. 61-76). London: Academic Press.

Valkenburg, P. M., Peter, J., \& Schouten, A. P. (2006). Friend Networking Sites and Their Relationship to Adolescents' Well-Being and Social Self-Esteem. Cyber Psychology \& Behavior, 9, 584-590. https://doi.org/10.1089/cpb.2006.9.584

Vogel, E. A., Rose, J. P., Roberts, L. R., \& Eckles, K. (2014). Social Comparison, Social Media, and Self-Esteem. Psychology of Popular Media Culture, 3, 206. https://doi.org/10.1037/ppm0000047

Wilcox, K., \& Stephen, A. T. (2012). Are Close Friends the Enemy? Online Social Networks, Self-Esteem, and Self-Control. Journal of Consumer Research, 40, 90-103. https://doi.org/10.1086/668794

Wills, T. A. (1981). Downward Comparison Principles in Social Psychology. Psychological Bulletin, 90, 245-271.

Woods, H. C., \& Scott, H. (2016). Sleepyteens: Social Media Use in Adolescence Is Associated with Poor Sleep Quality, Anxiety, Depression and Low Self-Esteem. Journal of Adolescence, 51, 41-49. https://doi.org/10.1016/j.adolescence.2016.05.008

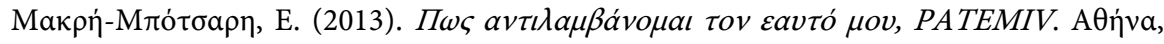

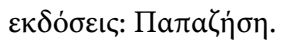

